\title{
Factors associated with the use of dental care by elderly residents of the state of São Paulo, Brazil
}

Emílio Prado da Fonsecal,

Suelen Garcia Oliveira da Fonseca² Marcelo de Castro Meneghim ${ }^{3}$

\section{Abstract}

Objective: To investigate factors associated with the use of dental care services. Methods: A cross-sectional study with a representative sample of elderly individuals aged 65 years or older residing in the state of São Paulo in 2015 was performed. Hierarchical multivariate logistic regression analysis was used based on the theoretical model of access determination proposed by Andersen (1995) to predict dental care visits. Results: The prevalence of public service use by the elderly was 1.981 (37.8\%), while $3.253(62.2 \%)$ used the private service/ health plan/ other type of service. Hierarchical multiple analysis $(p \leq 0.05)$ identified that less schooling or never having studied, non-white, lower income and motivated by pain/extraction were associated with the use of public dental services. The study showed a reduced use of public dental care among elderly persons who required some type of upper dentures (except complete dentures), need for some type of lower dentures (including complete dentures) and demonstrated a positive self-perception of oral health condition. Conclusions: A higher prevalence of the use of private dental care/ health plan/other type of service was identified. Less schooling or never having studied, non-white skin color, lower income and seeking the dentist with pain or to extract teeth were factors associated with the use of public dental services by the elderly.

Prefeitura Municipal de Divinópolis, Secretaria Municipal de Saúde, Diretoria de Vigilância em Saúde, Vigilância Sanitária. Divinópolis, MG, Brasil.

2 Universidade Estadual de Campinas, Faculdade de Odontologia de Piracicaba, Programa de Pós-Graduação em Odontologia. Piracicaba, SP, Brasil.

3 Universidade Estadual de Campinas, Faculdade de Odontologia de Piracicaba, Departamento de Odontologia Preventiva e Saúde Pública. Piracicaba, SP, Brasil.

Keywords: Health Services Accessibility. Multilevel Analysis. Oral Health. Unified Health System. 


\section{INTRODUCTION}

Brazil is undergoing a demographic and epidemiological transition due to the accelerated growth of the elderly population, with repercussions for the organization of health services, including dentistry ${ }^{1}$. The main oral illnesses, caries and periodontal disease have a cumulative nature and can compromise quality of oral health and result in significant tooth losses and complex and costly rehabilitation needs ${ }^{1-4}$. In this context, offering universal access is one of the main challenges faced by the Sistema Único de Saúde (the Unified Health System) (SUS) if it is to serve as a model of public health care policy for the elderly population ${ }^{1,2,5}$.

The most recent epidemiological survey of the oral health condition of the Brazilian population identified an index of caries (measured by the DMFT scale for the number of decayed, missing and filled teeth) of 27.53 for the 65-74 age group 3 . The missing component accounted for $92 \%$ of this index ${ }^{3}$. Periodontal conditions in the 65-74 age group showed that $90.5 \%$ had excluded sextants and of the few sextants that could be examined in this age group, $4.2 \%$ had calculus and 3.3\% had periodontal pockets, while $2.5 \%$ were shallow pockets ${ }^{3}$. In terms of the use and need of dentures, only $23.5 \%$ of the elderly did not use any type of upper denture and the percentage of users of complete dentures was $63.1 \%$. A total of $7.6 \%$ of individuals used partial removable dentures, while the proportion of individuals who did not require dentures was $7.3 \%$. These results indicate that the Brazilian elderly have high rates of edentulism, caries, periodontal disease and the need for dentures ${ }^{1,3}$.

Despite these poor oral health conditions and the low prevalence of the use of dental services, $46.6 \%$ of the elderly required dental treatment ${ }^{3,4}$. Overall, $14.7 \%$ have never visited the dentist at any time in their lives and $42.3 \%$ of those who have used the dentist last did so more than three years prior to the survey $^{3}$. Recent studies have indicated that access to dental services is modulated by contextual factors relating to both the oral health services and the individual ${ }^{2,5-9}$. The regular use of dental services contributes to the maintenance of oral health by means of less complex and preventive treatment, the early detection of diseases in distinct stages of life and improving the quality of life of the elderly ${ }^{2}$.

In Brazil the elderly can use the public dental service, acquire a private dental plan or pay directly for treatment. This structure provides greater access to elderly persons who can pay for a dental service or plan, which increases iniquities in the use of oral health services ${ }^{1,5,6}$. Unlike with medical services, the majority of Brazilian elderly people do not use the public dental service when seeking treatment ${ }^{5}$. In countries such as Brazil, which has a universal coverage system, the healthcare network is expected to offer better access to dental care for older populations. The present study is relevant as few studies have investigated the determinants relating to the use of the public dental service by the elderly $y^{4,5}$.

The aim of the present study was therefore to investigate factors associated with the use of public dental care services by elderly persons, based on the epidemiological survey of the Conditions of Oral Health of the Population of the State of São Paulo (SB-SP) carried out in 2015.

\section{METHOD}

An epidemiological cross-sectional populationbased study representing the state of São Paulo, Brazil, was performed ${ }^{10}$. To achieve this, 178 municipal regions plus the state capital (Primary Sampling Units - PSU) were drawn'. In the second stage 390 Census Sectors (Secondary Sampling Units - SSU) were drawn, with two sectors for each of the 177 municipal regions and 36 sectors for the city of São Paulo $^{10}$. The sample plan was elaborated by clusters in two stages of draws based on the Probability Proportional to Size (PPS) of the population ${ }^{10}$.

Individuals aged 65 and over were interviewed. This age group is recommended by the World Health Organization (WHO) for oral epidemiological studies and has become more important with changes in life expectanc $y^{10}$. Data from this group are necessary both for the effective planning of treatment for the elderly and for monitoring the general effects of dental services provided to a population ${ }^{10}$. 
The sampling plan design was elaborated by clusters in two stages of draws, considering the sample weight and the effect of the draws in the respective stages 9 . The state of São Paulo was stratified into six macro-regions described as domains ${ }^{10}$. In each domain 33 PSU were selected, with the exception of Macro I (the Metropolitan Region of the Capital), where 12 municipalities were drawn, in addition to the capital itself ${ }^{10}$. The draws were carried out based on the PPS of the population of each of the municipalities. In the second drawing stage, two SSU were drawn from each municipality, also respecting the probability proportional to the number of inhabitants in the sectors, while in the city of São Paulo, 36 SSU (corresponding to 18 collection points) were drawn. All the households in the selected sectors were analyzed for individuals belonging to the respective age group index ${ }^{10}$.

The sample was defined based on frequency estimation, the variability of the problem being investigated and the acceptable margin of error. Dental caries were used as the reference standard for the calculation of the sample, as this measure was used in the last two national surveys and is still the most common oral health problem ${ }^{10}$. However, the present study also used periodontal condition and usage and need for dentures data as a basis of calculation, taking as parameters the results of the Southeastern Region obtained by an earlier national study ${ }^{10}$. The sample size was calculated for each of the health problems and for the respective age group with the results of mean dental caries, periodontal condition and dentures (use and need), standard deviation and prevalence, acceptable margin of error $(\varepsilon)$, design effect (deff) and non-response rate (NNR) of the diseases for the age index, with this value considered as a population parameter for the calculation of the sample ${ }^{10}$. The formula for calculating the sample size for each of the diseases was adjusted for the size of the elderly population living in the state of São Paulo, according to the Population Projection System data for the municipalities of the state of São Paulo of the SEADE Foundation ${ }^{10}$. From the data of the population size index of the state, it was possible to apply the formula and, thus, to define a sample size that would allow statistical inference ${ }^{10}$. In this equation the deff and the NNR were added, thus adjusting the sample size formula to minimize the effect of the two-stage cluster draw ${ }^{10}$. The number of elderly persons examined was 5,951 individuals ${ }^{10}$.

The households visited were those of the census tracts drawn from each municipal region through the exhaustive technique with the minimum sample size for each $\mathrm{PSU}^{10}$. As it was not possible to perform a simple draw of the households based on the municipality as a whole, drawing stages per level were added to maintain the probabilistic basis of the study ${ }^{10}$. In this way, the census sector was the field of work of the team and guided the spatial distribution of the populations, and the sectors were drawn with probability proportional to the number of inhabitants in each of the municipal regions ${ }^{10}$. A questionnaire was applied to the individuals examined, which contained questions related to socioeconomic characterization, the use of dental services and self-reported oral morbidity or the selfperception of oral health ${ }^{10}$.

The calibration of the dental and support teams was carried out to simulate the conditions that the examiners would encounter, discuss the operationalization of the stages of the study and the attributions of the participants, and ensure an acceptable degree of uniformity in the procedures ${ }^{10}$. The consensus technique was used, calculating the Kappa coefficient in the final round, weighted for each examiner, age group and injury studied, with a value of 0.65 as the minimum acceptable limit ${ }^{10}$. The consensus revealed no concerns in comparisons with a standard examiner ${ }^{10}$.

The dependent variable of the present study was the type of dental service last used: public or private/ health plan/other. Individuals who never visited the dentist, were unable to provide information or did not respond were excluded from the analysis.

The selection of the independent variables was based on the theoretical model of the determination of the use of health services revisited by Andersen and employed in studies on the use of dental services ${ }^{4,5,11,12}$. According to the model, the use of health services is a result of the interaction of individual and contextual characteristics, the health system and the history of use of such services ${ }^{4,5,11,12}$. The author assumes that the determinants are divided 
into three groups: predisposing (related to the individual and sociodemographic factors), facilitating (income, characteristics of the health service) and need (perception of the health condition and health needs presented) factors ${ }^{4,5,11,12}$. The predisposing variables used were: gender, schooling, ethnicity/ race and history of toothache. The facilitating variables were: family income, when a dentist was last consulted, reason for last visit and satisfaction with the treatment. The need variables were the presence of dental calculus, need for endodontic treatment, need for upper and lower dentures and satisfaction with oral/dental condition.

Data analysis involved the calculation of prevalence and bivariate analysis through the chisquare test to associate the independent variables with the outcome ${ }^{4,5,12,13}$. The variables with significance lower than 0.20 in the bivariate analysis were then accepted for the construction of the multiple logistic regression model and Odds Ratio (OR) with 95\% confidence interval. The model was constructed to predict the probability of the elderly using the public dental service ${ }^{4,5,12,13}$. Gender, family income or schooling were considered as confounding variables $^{12,13}$. Three alternative logistical models were therefore constructed: in the first, the gender variable was excluded; in the second, schooling was included, but not family income; in the third, family income was included, but not schooling ${ }^{12}$. We chose to show the model that excluded the gender variable, as it exhibited greater strength of association with the use of public dental services ${ }^{12}$. Furthermore, the association with the gender variable remained statistically significant in the crude model. However, the OR measures produced by this technique may overestimate associations, and the possibility that the results obtained are overestimated cannot be ruled out ${ }^{4,12,13}$. In this sense, hierarchical logistic regressions were performed to estimate the multiple models, inserting each of the three blocks of variables according to the distal and proximal factors of the theoretical model used ${ }^{5}$. The final model presents the adjusted values of the variables that remained associated at the level of $p \leq 0.05$, with $95 \%$ confidence intervals in each of the steps of the hierarchical analysis 5 .

The research project was approved by the Ethics Research Committee under number 111/2015 and complied with Resolution 466, dated 12 December 2012, of the National Health Council relating to research involving human beings. A Free and Informed Consent Form (FICF) was applied and signed by each individual examined in the study.

\section{RESULTS}

Of the sample of 5,951 elderly persons, 5,234 (87.9\%) took part in the study, as $717(12.1 \%)$ were excluded because they had never visited the dentist, could not provide the information or did not answer the question about where their last dental appointment took place.

Table 1 presents the description and bivariate analysis of the type of dental service used and the independent variables. Among the elderly interviewed, 1,981 (37.8\%) used the public service on their most recent visit to the dentist while 3,253 $(62.2 \%)$ used the private service/health plan/other type of service. Regarding the predisposing factors, female $(3,270,62.5 \%)$, less educated $(3,563,69.5 \%)$, white $(3,660,69.9 \%)$ subjects without a history of toothache $(3,959,76,1 \%)$ were found to be most prevalent. For the facilitating factors, elderly persons with lower family incomes $(51.5 \%)$, who last used the dental service three or more years previously (45.5\%) and were motivated by treatment $(42.7 \%)$ prevailed in the sample, while satisfaction with treatment was not associated with the use of dental services in the bivariate analysis. Regarding the factors of need, the presence of dental calculus was identified in 1,265 (58.5\%) elderly persons, with $62(1.2 \%)$ requiring endodontic treatment and 2,042 (40.2\%) exhibiting dissatisfaction or indifference with their oral/dental condition. A total of 1,913 (36.6\%) of the elderly persons identified the need for complete upper dentures and 1,752 (33.6\%) required complete lower dentures. 
Table 1. Prevalence and bivariate analysis of the predisposing, facilitating and need factors associated with the use of dental services by elderly people in the state of São Paulo, 2015.

\begin{tabular}{|c|c|c|c|c|c|c|}
\hline \multirow[t]{2}{*}{ Variables } & \multicolumn{2}{|c|}{ Participants } & \multicolumn{2}{|c|}{ Private/Plan/Other } & \multirow[t]{2}{*}{ Total (\%) } & \multirow[t]{2}{*}{$p$-value* } \\
\hline & $\mathrm{n}=1,981$ & $\%=37.8$ & $\mathrm{n}=3,253$ & $\%=62.2$ & & \\
\hline \multicolumn{7}{|l|}{ Predisposing } \\
\hline Gender & & & & & & 0.003 \\
\hline Male & 794 & 40.4 & 1,170 & 59.6 & $1,964(37.5)$ & \\
\hline Female & 1,187 & 36.3 & 2,083 & 63.7 & $3,270(62.5)$ & \\
\hline Schooling (years) & & & & & & $<0.001$ \\
\hline Never studied & 469 & 45.4 & 564 & 54.6 & $1,033(20.2)$ & \\
\hline 1 to 9 & 1,379 & 38.7 & 2,184 & 61.3 & $3,563(69.5)$ & \\
\hline 10 to 25 & 88 & 16.6 & 441 & 83.4 & $529(10.3)$ & \\
\hline Race/Ethnicity & & & & & & $<0.001$ \\
\hline White & 1,283 & 35.1 & 2,377 & 64.9 & $3,660(69.9)$ & \\
\hline Non-white & 698 & 44.3 & 876 & 55.7 & $1,574(30.1)$ & \\
\hline Toothache & & & & & & $<0.001$ \\
\hline Yes & 558 & 44.8 & 687 & 55.2 & $1,245(23.9)$ & \\
\hline No & 1,414 & 35.7 & 2,545 & 64.3 & $3,959(76.1)$ & \\
\hline \multicolumn{7}{|l|}{ Facilitating } \\
\hline Family income (reais) & & & & & & $<0.001$ \\
\hline Less than $1,500.00$ & 1,125 & 45.7 & 1,337 & 54.3 & $2,462(51.5)$ & \\
\hline From $1,501.00$ to $2,500.00$ & 546 & 35.8 & 979 & 64.2 & $1,525(31.9)$ & \\
\hline More than 2,501.00 & 147 & 18.5 & 649 & 81.5 & $796(16.6)$ & \\
\hline Time (years) & & & & & & $<0.001$ \\
\hline Less than 1 & 663 & 41.9 & 916 & 58.1 & $1,579(32.9)$ & \\
\hline Between 1 and 2 & 410 & 39.6 & 626 & 60.4 & $1,036(21.6)$ & \\
\hline 3 or more & 727 & 33.3 & 1,457 & 66.7 & $2,184(45.5)$ & \\
\hline Motive & & & & & & $<0.001$ \\
\hline Check-up & 368 & 41.6 & 517 & 58.4 & $885(17.5)$ & \\
\hline Treatment & 623 & 28.8 & 1,537 & 71.2 & $2,160(42.7)$ & \\
\hline Pain/extraction/other & 863 & 42.8 & 1,152 & 57.2 & $2,015(39.8)$ & \\
\hline Satisfaction with treatment & & & & & & 0.235 \\
\hline Satisfied & 1,665 & 37.1 & 2,819 & 62.9 & $4,484(88.6)$ & \\
\hline Dissatisfied/indifferent & 198 & 34.5 & 376 & 65.5 & $574(11.4)$ & \\
\hline \multicolumn{7}{|l|}{ Need } \\
\hline Dental calculus & & & & & & $<0.001$ \\
\hline Yes & 520 & 41.1 & 745 & 58.9 & $1,265(58.5)$ & \\
\hline No & 291 & 32.5 & 605 & 67.5 & $896(41.5)$ & \\
\hline Endodontics & & & & & & 0.001 \\
\hline Yes & 37 & 59.7 & 25 & 40.3 & $62(1.2)$ & \\
\hline No & 1,944 & 37.6 & 3.228 & 62.4 & $5,172(98.8)$ & \\
\hline
\end{tabular}


Continuation of Table 1

\begin{tabular}{|c|c|c|c|c|c|c|}
\hline \multirow[t]{2}{*}{ Variables } & \multicolumn{2}{|c|}{ Participants } & \multicolumn{2}{|c|}{ Private/Plan/Other } & \multirow[t]{2}{*}{ Total $(\%)$} & \multirow[t]{2}{*}{$p$-value* } \\
\hline & $\mathrm{n}=1,981$ & $\%=37.8$ & $\mathrm{n}=3,253$ & $\%=62.2$ & & \\
\hline Upper dentures & & & & & & $<0.001$ \\
\hline Complete dentures & 808 & 42.2 & 1.105 & 57.8 & $1,913(36.6)$ & \\
\hline Some & 300 & 47.3 & 334 & 52.7 & $634(12.1)$ & \\
\hline No & 873 & 32.5 & 1.812 & 67.5 & $2,685(51.3)$ & \\
\hline Lower dentures & & & & & & $<0.001$ \\
\hline Complete dentures & 744 & 42.5 & 1.008 & 57.5 & $1,752(33.6)$ & \\
\hline Some & 587 & 43.4 & 766 & 56.6 & $1,353(25.8)$ & \\
\hline No & 650 & 30.6 & 1.475 & 69.4 & $2,125(40.6)$ & \\
\hline Oral/dental satisfaction & & & & & & $<0.001$ \\
\hline Satisfied & 1,059 & 34.8 & 1,982 & 65.2 & $3,041(59.8)$ & \\
\hline Indifferent/dissatisfied & 849 & 41.5 & 1,196 & 58.5 & $2,045(40.2)$ & \\
\hline
\end{tabular}

${ }^{*} p$-value: probability of significance by Pearson Chi-Squared Test.

In the bivariate analysis, the associated predisposing, facilitating and need factors $(p \leq 0.20)$ for the use of dental services were identified. This analysis supported the hierarchical logistic model (Table 1).

The hierarchical multiple analysis $(\mathrm{p} \leq 0.05)$ is presented in table 2. It was observed that being less educated or never having studied, non-white, lower income and motivated by pain/extraction were associated with the use of public dental services. In addition, elderly persons were 1.4 (95\% CI: 1.05; 1.87) times more likely to wait three or more years to visit the public dental service in comparison with those who used the private service. In addition, there was a lower use of the public dental service among elderly persons who needed some type of upper dentures (except complete dentures), need for some type of lower dentures (including complete dentures) and those with a positive self-perception of their oral health condition.

Table 3 shows the crude and adjusted models for the significant variables $(p \leq 0.05)$ of the hierarchical model and their respective $\mathrm{R}^{2}$ values, with the adjusted model explaining by $14 \%$ the fact that elderly people living in the state of São Paulo use the public dental service. 
Table 2. Hierarchical multiple logistic regression analysis of factors associated with the use of public dental services by elderly people in the state of São Paulo, 2015.

\begin{tabular}{|c|c|c|c|c|c|c|c|c|c|}
\hline \multirow[t]{2}{*}{ Variables } & \multicolumn{3}{|c|}{ Block 1} & \multicolumn{3}{|c|}{ Block 2} & \multicolumn{3}{|c|}{ Block 3} \\
\hline & OR & CI $(95 \%)$ & $p$-value* & OR & CI $(95 \%)$ & $p$-value* & OR & CI $(95 \%)$ & $p$-value* \\
\hline \multicolumn{10}{|l|}{ Predisposing } \\
\hline \multicolumn{10}{|l|}{ Schooling (years) } \\
\hline Never studied & 0.26 & $(0.20-0.33)$ & $<0.001$ & 0.27 & $(0.20-0.37)$ & $<0.001$ & 0.22 & $(0.14-0.35)$ & $<0.001$ \\
\hline 1 to 9 & 0.79 & $(0.68-0.91)$ & 0.001 & 0.72 & $(0.61-0.85)$ & $<0.001$ & 0.66 & $(0.48-0.89)$ & 0.007 \\
\hline 10 to 25 & 1 & & & 1 & & & 1 & & \\
\hline \multicolumn{10}{|l|}{ Race/Ethnicity } \\
\hline White & 0.72 & $(0.63-0.81)$ & $<0.001$ & 0.78 & $(0.67-0.89)$ & $<0.001$ & 0.71 & $(0.57-0.88)$ & 0.002 \\
\hline Non-white & 1 & & & 1 & & & 1 & & \\
\hline \multicolumn{10}{|l|}{ Toothache } \\
\hline Yes & 1 & & & 1 & & & - & - & - \\
\hline No & 0.71 & $(0.62-0.81)$ & $<0.001$ & 0.92 & $(0.78-1.07)$ & 0.276 & - & - & - \\
\hline \multicolumn{10}{|l|}{ Facilitating } \\
\hline \multicolumn{10}{|l|}{ Family income (reais) } \\
\hline Less than $1,500.00$ & & & & 0.77 & $(0.67-0.89)$ & $<0.001$ & 0.73 & $(0.58-0.92)$ & $<0.001$ \\
\hline From $1,501.00$ to $2,500.00$ & & & & 0.32 & $(0.26-0.40)$ & $<0.001$ & 0.33 & $(0.24-0.45)$ & 0.008 \\
\hline More than 2,501.00 & & & & 1 & & & 1 & & \\
\hline \multicolumn{10}{|l|}{ Last visit } \\
\hline Less than one year & & & & 1 & & & 1 & & \\
\hline Between one and 2 years & & & & 1.70 & $(1.45-1.99)$ & $<0.001$ & 1.83 & $(1.41-2.38)$ & $<0.001$ \\
\hline 3 years or more & & & & 1.51 & $(1.28-1.80)$ & $<0.001$ & 1.40 & $(1.05-1.87)$ & 0.020 \\
\hline \multicolumn{10}{|l|}{ Motive } \\
\hline Check-up & & & & 1 & & & 1 & & \\
\hline Treatment & & & & 1.08 & $(0.89-1.31)$ & 0.424 & 0.95 & $(0.71-1.26)$ & 0.713 \\
\hline Pain/extraction/other & & & & 0.57 & $(0.49-0.66)$ & $<0.001$ & 0.58 & $(0.46-0.74)$ & $<0.001$ \\
\hline \multicolumn{10}{|l|}{ Need } \\
\hline \multicolumn{10}{|l|}{ Dental calculus } \\
\hline Yes & & & & & & & 1 & & \\
\hline No & & & & & & & 0.83 & $(0.67-1.03)$ & 0.085 \\
\hline \multicolumn{10}{|l|}{ Endodontics } \\
\hline Yes & & & & & & & 1 & & \\
\hline No & & & & & & & 0.92 & $(0.43-1.95)$ & 0.827 \\
\hline \multicolumn{10}{|l|}{ Upper dentures } \\
\hline No & & & & & & & 1 & & \\
\hline Some type & & & & & & & 0.74 & $(0.55-0.99)$ & 0.043 \\
\hline Complete dentures & & & & & & & 1.17 & $(0.87-1.57)$ & 0.299 \\
\hline \multicolumn{10}{|l|}{ Lower dentures } \\
\hline No & & & & & & & 1 & & \\
\hline Some type & & & & & & & 0.41 & $(0.26-0.66)$ & $<0.001$ \\
\hline Complete dentures & & & & & & & 0.62 & $(0.41-0.95)$ & 0.028 \\
\hline \multicolumn{10}{|l|}{ Oral/dental satisfaction } \\
\hline Satisfied & & & & & & & 0.77 & $(0.62-0.95)$ & 0.015 \\
\hline Indifferent/unsatisfied & & & & & & & 1 & & \\
\hline $\mathrm{R}^{2}$ & & 0.05 & & & 0.12 & & & 0.21 & \\
\hline
\end{tabular}

${ }^{*}$-value: probability of significance by Pearson chi-squared test. 
Table 3. Crude and adjusted model of hierarchical multiple logistic regression analysis of factors associated with the use of public dental services by elderly people in the state of São Paulo, 2015.

\begin{tabular}{|c|c|c|c|c|c|c|}
\hline \multirow[t]{2}{*}{ Variables } & \multicolumn{3}{|c|}{ Crude* } & \multicolumn{3}{|c|}{ Adjusted $^{* *}$} \\
\hline & OR & $\mathrm{CI}(95 \%)$ & $p$-value & OR & CI $(95 \%)$ & $p$-value \\
\hline \multicolumn{7}{|l|}{ Predisposing } \\
\hline \multicolumn{7}{|l|}{ Schooling (years) } \\
\hline Never studied & 0.22 & $(0.14-0.35)$ & $<0.001$ & 0.27 & $(0.20-0.36)$ & $<0.001$ \\
\hline 1 to 9 & 0.64 & $(0.47-0.87)$ & 0.004 & 0.71 & $(0.60-0.84)$ & $<0.001$ \\
\hline 10 to 25 & 1 & & & 1 & & \\
\hline \multicolumn{7}{|l|}{ Race/Ethnicity } \\
\hline White & 0.71 & $(0.57-0.89)$ & 0.003 & 0.82 & $(0.71-0.95)$ & 0.007 \\
\hline Non-white & 1 & & & 1 & & \\
\hline \multicolumn{7}{|l|}{ Toothache } \\
\hline Yes & 1 & & & - & - & - \\
\hline No & 0.74 & $(0.59-0.94)$ & 0.015 & - & - & - \\
\hline \multicolumn{7}{|l|}{ Facilitators } \\
\hline \multicolumn{7}{|l|}{ Family income (reais) } \\
\hline Less than 1,500 & 0.74 & $(0.59-0.94)$ & 0.010 & 0.77 & $(0.66-0.89)$ & $<0.001$ \\
\hline From 1,501 to $2,500.00$ & 0.34 & $(0.24-0.46)$ & $<0.001$ & 0.33 & $(0.26-0.41)$ & $<0.001$ \\
\hline More than 2,501.00 & 1 & & & 1 & & \\
\hline \multicolumn{7}{|l|}{ Last visit } \\
\hline Less than one year & 1 & & & 1 & & \\
\hline Between one and 2 years & 1.76 & $(1.35-2.29)$ & $<0.001$ & 1.85 & $(1.56-2.18)$ & $<0.001$ \\
\hline 3 years or more & 1.42 & $(1.07-1.89)$ & 0.017 & 1.56 & $(1.31-1.86)$ & $<0.001$ \\
\hline \multicolumn{7}{|l|}{ Motive } \\
\hline Check-up & 1 & & & 1 & & \\
\hline Treatment & 0.98 & $(0.73-1.31)$ & 0.893 & 1.19 & $(0.98-1.44)$ & 0.084 \\
\hline Pain/extraction/other & 0.60 & $(0.47-0.77)$ & $<0.001$ & 0.59 & $(0.50-0.68)$ & $<0.001$ \\
\hline
\end{tabular}

Need

Dental calculus

Yes

No 0.83

Endodontics

Yes 1

No 0.95

$0.95 \quad(0.45-2.01) \quad 0.887$

Upper dentures

No

Some type

Complete dentures

$\begin{array}{llllll}0.75 & (0.55-1.01) & 0.056 & 0.96 & (0.78-1.18) & 0.686\end{array}$

Lower dentures

$\begin{array}{llllll}1.15 & (0.86-1.56) & 0.345 & 1.36 & (1.06-1.75) & 0.018\end{array}$

No

Some type $\quad \begin{array}{llllll}0.41 & (0.26-0.66) & <0.001 & 0.65 & (0.52-0.82) & <0.001\end{array}$

$\begin{array}{lllllll}\text { Complete dentures } & 0.62 & (0.40-0.95) & 0.028 & 0.87 & (0.70-1.07) & 0.179\end{array}$

Oral/dental satisfaction

$\begin{array}{lllllll}\text { Satisfaction } & 0.79 & (0.64-0.98) & 0.035 & 0.80 & (0.69-0.92) & 0.001\end{array}$

Indifferent/dissatisfied

1

$\begin{array}{lll}\mathrm{R}^{2} & 0.22 & 0.14\end{array}$

${ }^{*} p$-value: probability of significance of crude model by Wald Test; ${ }^{* *} p$-value: probability of significance of adjusted model without gender variable by Wald Test. 


\section{DISCUSSION}

Brazilian elderly persons must carry the burden of inheriting a disease-centered care model with invasive curative dentistry practices and limitations in access to public dental services ${ }^{1,14}$. A study suggests that the use of dental services in adults and the elderly is related to the corresponding habits in childhood ${ }^{15}$.

Analysis of the use of public health services allows an indirect evaluation of the equity of a health system ${ }^{12}$. A study in Montes Claros, Minas Gerais, found a lower prevalence of public service use among the elderly $y^{3,5}$. A study conducted in European countries with a universal coverage system found a variation of $50 \%$ to $82 \%$ in the use of public dental services, except in Poland, where the prevalence of such use was $23 \%{ }^{15}$. Systematic review studies have identified the scarcity of public services as one of the main barriers to access to health services by the elderly ${ }^{1,16}$. The present study found that $37.8 \%$ of the elderly used the public dental service.

Acceptable standards of health service use are influenced by socioeconomic and demographic determinants ${ }^{16,17}$. In this sense, poorer elderly persons may suffer greater difficulties in obtaining health care, which reinforces social inequities in the use of dental services among this age group ${ }^{16-18}$. Previous studies have shown that elderly women with higher incomes and levels of schooling used dental services more ${ }^{4,17,18}$. A higher income can facilitate paying for dental services, the purchasing of dental products and adherence to health insurance, while greater schooling can be translated into a higher level of information about the importance of regular visits to the dentist ${ }^{1,18}$. A study found that Brazilians spent an average of $\mathrm{R} \$ 42.19$ reais on dental care services and $\mathrm{R} \$ 10.27$ reais on oral hygiene products ${ }^{19}$. In addition, spending on health and insurance plans increases with age, favoring the access of richer elderly persons to this type of coverage ${ }^{19}$. In the USA, elderly persons over the age of 65 are covered by public health insurance (Medicare), which covers individual expenditure on medical costs ${ }^{6}$. In Brazil, the elderly can either use the public service, pay directly, or pay for private health insurance. This structure allows greater access to health services for elderly persons who can pay for the service, which reinforces the iniquities in oral health and explains the findings.
Studies in countries such as Japan and the USA have identified difficulties in public transportation, place of residence, low mobility, an inability to drive, and lack of family transport support as barriers to accessing dental care ${ }^{20,21}$. Another study pointed out that the association between socioeconomic factors and the use of health services may vary according to the countries (the health system adopted) and the type of service used ${ }^{16}$. However, a study in Ponta Grossa in Parana did not identify an association between lower family income and delays in consulting the dentist among the elderly ${ }^{4}$. The removal of economic barriers would not necessarily make the prevalence of health service utilization in different contextual levels more equal ${ }^{4}$.

Race is a limiting factor in the use of dental services by the elderly ${ }^{22}$. A study conducted among the Brazilian elderly showed that the chance of black elderly persons not having used the dental service at least once in their lives is 0.62 OR times less than among white elderly persons ${ }^{22}$. The findings of the present study indicated that there is less chance of a white elderly person using public oral health services. In this sense, social determinants may explain poor access to oral health services by nonwhite elderly persons ${ }^{22}$. Differences in access to oral health services among whites and non-whites can in part be attributed to the effects of discrimination ${ }^{22}$.

Studies that used data from the National Household Sampling Survey (PNAD) of 1998, 2003 and 2008 identified a reduction in the percentage of elderly people who had never been to the dentist, despite this group having the lowest prevalence of regular dental service use (less than one year) ${ }^{7-9}$. A previous study with elderly people in São Paulo showed high rates of use of health services, with $83.3 \%$ reporting having had at least one visit in the 12 months prior to the interview ${ }^{12}$. However, only $32.9 \%$ of the elderly interviewed reported having visited the dentist in the previous year and the findings of this and other studies ${ }^{4,5,18}$ indicate that elderly persons wait longer before visiting the dental service. This fact can be explained by the fact that dental appointments tend to decrease with aging due to the high prevalence of dental loss and edentulism ${ }^{4}$. In addition, the ability of the elderly to access and use health services may be related, in addition to income and schooling, to the possession of private 
health insurance and difficulties in accessing public dental services ${ }^{1,4,12}$.

Elderly people reported greater chances of seeking outpatient and inpatient health services ${ }^{12,16}$. In terms of oral condition, the presence of toothache was the reason why $23.9 \%$ of the elderly visited the dentist, a finding similar to a previous study ${ }^{4}$. The main reasons cited for non-use of the services, if specified, were related to the issues of disease severity, selfmedication, quality of service, distance and cost of services $^{12,21}$. The elderly with lower income cited reasons such as the non-serious nature of the health problem, distance and the quality of health services ${ }^{23}$. The study also identified a lower prevalence (17.5\%) of the use of preventive dental services. Studies in Montes Claros, Minas Gerais, with elderly people aged 65 to 74 years, identified greater demand for dental treatment than for check-ups or prevention ${ }^{5}$. The high prevalence of seeking dental care for treatment, pain or extraction shows the reflexes of oral diseases and of curative/invasive practices experienced in this age group ${ }^{1,5}$. On the other hand, the increase in the dentate and edentulous elderly population may represent an increase in health demands and the need for dental treatment. Changing this profile requires strategies and attitudes of coresponsibility, as the curative approach is limited by offering uneconomical actions of prevention and health promotion, with repercussions for the health system and the population ${ }^{1}$.

For Andersen (1995), individuals and families should perceive health problems and seek care ${ }^{11}$. Perceived needs (need for upper and lower dentures) are individual factors that identify barriers to access and the use of dental services ${ }^{4,11}$. In the present study, the need for dentures (both complete and some type of dentures) was associated with access to public dental services. These findings may indicate the existence of suppressed demands by specialized dental services. When undergoing one or more tooth extraction the elderly will need future prosthetic rehabilitation treatment, which is costly both for the elderly and for the public service. In Brazil, the Centro de Especialidades Odontológicas (the Center of Dental Specialties) and the Laboratórios Regionais de Prótese Dentária (the Regional Dental Prosthesis Laboratories) are responsible for the supply and manufacture of dentures in the public service $^{5}$. Paradoxically, the increase in the number of people with teeth, difficulty accessing this type of rehabilitation and the high costs of the private service were related to the lack of recent use of dental services ${ }^{4,5,18}$. In this sense, studies on access to public dental services are important tools for reorienting the care model for non-priority population groups through oral health policy and planning.

Regarding satisfaction with mouth/teeth, $40.2 \%$ of elderly individuals described self-rated dissatisfaction or indifference in relation to their oral health. The precarious oral health condition of the Brazilian elderly may account for the negative evaluation of dental services, and dental loss can be perceived as a natural process of aging ${ }^{24,25}$. Studies carried out in the cities of São Paulo and Florianópolis (Santa Catarina) showed that the elderly self-evaluated their oral health as good or very good ${ }^{24,26}$. The perception of oral health among the elderly can be affected by personal beliefs and values, as pain and disability are inevitable at this age $e^{25,26}$, despite the high prevalence of need for upper and lower dentures identified in this study. Even if not associated with the use of the public service, the presence of calculus can be an important indicator for not visiting the dentist.

The cross-sectional study design did not allow causality to be established in relation to the determinants of access to the public dental service by the elderly. The greater use of dental services by women was not part of the bivariate and multiple analysis as their participation in the research may have been overestimated and could have compromised the external validity of the study. The use of the OR impacted on the variance of the estimates, suggesting parsimony in the interpretation of the results when using this technique. However, the study has a broad scope, a wealth of data from clinical exams and a methodological dedication that gives it internal validity. In addition, the NNR and the exclusion of the elderly who reported never having visited the dentist or said that they consulted other types of dental services may represent a different pattern of the use of dental services. Finally, some of the variables used depend to a certain extent on the respondent's memory and so information bias may have occurred. As an example, some individuals may have reported recent consultations with the dentist to avoid demonstrating negligence. Individuals 
residing in rural areas or isolated communities may be confronted with the reduced supply of dental services due to residing in these types of areas, which can entail difficulties of movement, lack of public transport or precarious road conditions. It is therefore suggested that studies that identify patterns and barriers to the use of dental services by elderly people living in rural or remote areas are carried out.

\section{CONCLUSION}

There was a lower frequency of use of public dental services by the elderly in the present study.

\section{REFERENCES}

1. Moreira RS, Nico LS, Tomita NE, Ruiz T. A saúde bucal do idoso brasileiro: revisão sistemática sobre o quadro epidemiológico e acesso aos serviços de saúde bucal. Cad Saúde Pública. 2005;21(6):1665-75.

2. Austregésilo SC, Leal MCC, Marques APO, Vieira JCM, Alencar DL. Acessibilidade a serviços de saúde bucal por pessoas idosas: uma revisão integrativa. Rev Bras Geriatr Gerontol. 2015;18(1):189-99.

3. Brasil. Ministério da Saúde, Secretaria de Atenção à Saúde, Secretaria de Vigilância em Saúde. SB Brasil 2010: Pesquisa Nacional de Saúde Bucal: resultados principais. Brasília, DF: MS; 2012.

4. Martins AMEBL, Ferreira RC, Santos-Neto PE, Carreiro DL, Souza JGS, Ferreira EF. User's dissatisfaction with dental care: a population based household study. Rev Saúde Pública. 2015;49:1-14.

5. Oliveira RFR, Souza JGS, Haikal DS, Ferreira EF, Martins AMEBL. Equidade no uso de serviços odontológicos provenientes do SUS entre idosos: estudo de base populacional. Ciênc Saúde Coletiva. 2016;21(11):3509-23.

6. Bós AMG, Bós AJG. Determinantes na escolha entre atendimento de saúde privada e pública por idosos. Rev Saúde Pública. 2004;38(1):113-20.

7. Gulcan F, Ekback G, Ordell S, Lie SA, Astrom AN. Social predictors of less frequent dental attendance over time among older people: population averaged and person-specific estimates. Community Dent Oral Epidemiol. 2016;44(3):263-73.
The multiple model identified schooling, nonwhite skin color/ethnicity, family income, long periods without consulting the dentist, motivation of pain or extraction, the need for complete upper dentures, some type of lower denture and negative self-perception of oral/dental condition as factors associated with the use of public dental services by the elderly. Local health systems should therefore be organized to minimize the impacts of social and oral vulnerabilities that accompany advancing age. The expectation is that the results of the present study will support the expansion of non-specialized and specialized dental public services for the elderly population residing in the state of São Paulo.
8. Manhães ALD, Costa AJL. Acesso a e utilização de serviços odontológicos no Estado do Rio de Janeiro, Brasil, em 1998: um estudo exploratório a partir da Pesquisa Nacional por Amostra de Domicílios. Cad Saúde Pública. 2008;24(1):207-18.

9. Peres KG, Peres MA, Boing AF, Bertoldi AD, Bastos JL, Barros AJD. Redução das desigualdades sociais na utilização de serviços odontológicos no Brasil entre 1998 e 2008. Rev Saúde Pública. 2012;46(2):250-8.

10. Frias AC, Pereira AC, Vieira V. Pesquisa Estadual de Saúde Bucal: relatório final [Internet]. São Paulo: Livronovo; 2015 [acesso em 10 maio 2017]. Disponível em: http://w2.fop.unicamp.br/sbsp2015/ down/ebook_relatorio_SBSP_2015.pdf

11. Andersen RM. Revisiting the behavioral model and access to medical care: does it matter? J Health Soc Behav. 1995;36(1):1-10.

12. Louvison MCP, Lebrão ML, Duarte YAO, Santos JLF, Malik AM, Almeida ES. Desigualdades no uso e acesso aos serviços de saúde entre idosos do município de São Paulo. Rev Saúde Pública. 2008;42(4):733-40.

13. Matos DL, Lima-Costa MFF, Guerra HL, Marcenes W. Projeto Bambuí: estudo de base populacional dos fatores associados com o uso regular de serviços odontológicos em adultos. Cad Saúde Pública. 2001;17(3):661-8.

14. Dutra CESV, Sanchez HF. Organização da atenção à saúde bucal prestada ao idoso nas equipes de saúde bucal da Estratégia Saúde da Família. Rev Bras Geriatr Gerontol. 2015;18(1):179-88. 
15. Manski R, Moeller J, Chen H, Widström E, Listl S. Disparity in dental attendance among older adult populations: a comparative analysis Across Selected European Countries and the United States. Int Dent J. 2016;66(1):36-48.

16. Almeida APSC, Nunes BP, Duro SMS, Facchini LA. Determinantes socioeconómicos do acesso a serviços de saúde em idosos: revisão sistemática. Rev Saúde Pública. 2017;51:50.

17. Ritter F, Fontanive P, Warmling CM. Condições de vida e acesso aos serviço de saúde bucal de idosos da periferia de Porto Alegre. Bol Saúde. 2004;18(1):79-85.

18. Ferreira CO, Antunes JLF, Andrade FB. Fatores associados à utilização dos serviços odontológicos por idosos brasileiros. Rev Saúde Pública. 2013;47(Supl 3):90-7.

19. Cascaes AM, Camargo MBJ, Castilhos ED, Silva AMR, Barros AJD. Gastos privados com saúde bucal no Brasil: análise dos dados da Pesquisa de Orçamentos Familiares, 2008-2009. Cad Saúde Pública. 2017;32(1):1-13.

20. Borrel LN, Northridge ME, Muller DB, Golembeski CA, Spielman SE, Sclar ED, et al. Oral health and health care for older adults: a spatial approach for addressing disparities and planning services. Spec Care Dentist. 2006;26(6):252-6.
21. Hanibuchi T, Aida J, Nakade M, Hirai H, kondo K. Geographical accessibility to dental care in the Japanese elderly. Community Dent Health. 2011;28(2):128-35.

22. Souza EHA, Oliveira PAP, Peagle AC, Goes PSA. Raça e o uso dos serviços de saúde bucal por idosos. Ciênc Saúde Coletiva. 2012;17(8):2063-70.

23. Grönbeck-Linden I, Hägglin C, Petersson A, Linander PO, Gahnberg L. Discontinued dental attendance among elderly people in Sweden. Int J Dent Hyg. 2016;6(3):224-29.

24. Andrade FB, Lebrão ML, Santos JLF, Duarte YAO, Teixeira DSC. Fatores associados à autopercepção de saúde bucal ruim entre idosos não institucionalizados do Município de São Paulo, Brasil. Cad Saúde Pública. 2012;28(10):1965-75.

25. Martins AMEBL, Jardim LA, Souza JGS, Rodrigues CAQ, Ferreira RC, Pordeus IA. A avaliação negativa dos serviços odontológicos entre idosos brasileiros está associada ao tipo de serviço utilizado? Rev Bras Epidemiol. 2014;17(1):71-90.

26. Benedetti TRB, Mello ALSF, Gonçalves LHT. Idosos de Florianópolis: autopercepção das condições de saúde bucal e utilização de serviços odontológicos. Ciênc Saúde Coletiva. 2007;12(6):1683-90. 